\title{
Lonely Atoms with Special Gifts: Breaking Linear Scaling Relationships in Heterogeneous Catalysis with Single-Atom Alloys
}

\author{
Matthew T. Darby ${ }^{\mathrm{a}}$, Michail Stamatakis ${ }^{\mathrm{a}}$, Angelos Michaelides ${ }^{\mathrm{b}}$ and E. Charles. H. Sykes ${ }^{\mathrm{c}}$ \\ a Department of Chemical Engineering, University College London, 203 Roberts Building, \\ Torrington Place, London, WC1E 7JE, United Kingdom \\ $b$ Thomas Young Centre, London Centre for Nanotechnology and Department of Physics and \\ Astronomy, University College London, Gower Street, London WC1E 6BT, United Kingdom \\ c Department of Chemistry, Tufts University, 62 Talbot Ave., Medford, Massachusetts 02155, \\ United States.
}




\begin{abstract}
:
We discuss a simple yet effective strategy for escaping traditional linear-scaling relations in heterogeneous catalysis with highly dilute bimetallic alloys known as Single-Atom Alloys (SAAs). These systems, in which a reactive metal is atomically dispersed in a less reactive host, were first demonstrated with the techniques of surface science to be active and selective for hydrogenation reactions. Informed by these early results, $\mathrm{PdCu}$ and $\mathrm{PtCu} \mathrm{SAA}$ nanoparticle hydrogenation catalysts were shown to work under industrially relevant conditions. To efficiently survey the many potential metal combinations and reactions, simulation is crucial for making predictions about reactivity, and guiding experimental focus on the most promising candidate materials. This recent work reveals that the high surface chemical heterogeneity of SAAs can result in significant deviations from Brønsted-Evans-Polanyi scaling relationships for many key reaction steps. These recent insights into SAAs, and their ability to break linear scaling-relations, motivate discovery of novel alloy catalysts.
\end{abstract}

\title{
TOC:
}
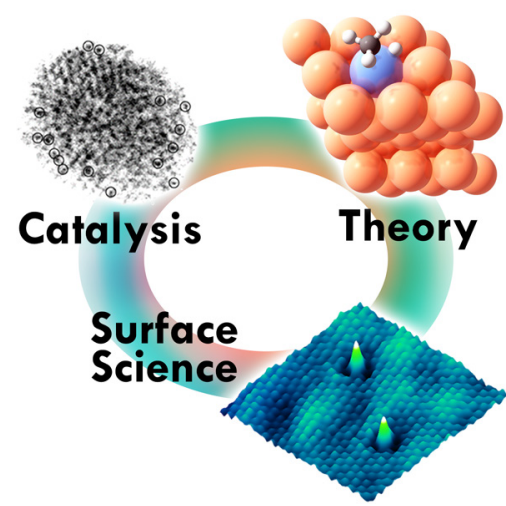
Catalysts are vital to society and modern industry with $\sim 85 \%$ of industrial processes relying on them. ${ }^{1-4}$ Catalysts are widely used because they facilitate chemical conversion at lower temperatures and pressures, thus making chemical processes less energy intensive. Despite their many advantages, heterogeneous catalysts are very complex and apparent reaction rates depend on many variables, including, but not limited to temperature, pressure, reactant stoichiometry, catalyst composition, particle size, strain and ligand effects. Therefore, rational design of next generation catalysts is an enormous challenge.

In an attempt to simplify this task, "shortcut methods" have been developed, which can provide valuable insight without having to capture all sources of complexity just noted. Descriptor-type approaches based on scaling relationships have thus proved invaluable in predicting reactivity trends. In particular, the Brønsted-Evans-Polanyi (BEP) relationship, suggests a linear dependence between the activation barrier and the reaction energy of a chemical transformation..$^{5-9}$ In turn, the reaction energy can be estimated from the binding energies of a few key intermediates in the chemistry of interest, with the use of thermodynamic scaling relationships. ${ }^{10}$ Finally, quantification of the binding energies can be achieved by invoking the $d-$ band model, which relates the d-band center of the catalytic metal to adsorption strength. ${ }^{11-13}$ This framework yields a good single descriptor of a metal surface's reactivity (the d-band center), and has therefore enabled many reactions to be understood in terms of fundamental surface adsorption properties. ${ }^{14-15}$ From a conceptual standpoint, the framework just discussed essentially quantifies the Sabatier principle, which was put forth over 100 years ago. ${ }^{16}$ This principle is captured by "volcano" shaped plots, which show that the best catalysts are materials which bind reactants and intermediates strongly enough to cause bonds to break (and other reaction events), but weakly enough to allow products to desorb intact. ${ }^{15-17}$ The ramification of this is that the choice of a catalytically active metal is a compromise and cannot yield both low activation barriers and weak binding simultaneously. ${ }^{15-17}$

Of course, there is no reason to restrict the design space of catalytic materials to pure metals. In fact, it was recognized early on that by considering alloys, one can access areas in the "volcano plot" that would be inaccessible for pure metals, thereby developing catalysts with improved performance. ${ }^{18}$ Over the last two decades, computer simulation methods, most notably density functional theory (DFT), have enabled many bimetallic alloy surfaces to be studied. ${ }^{8,} 19-25$ Many of these studies computed the binding strength of intermediates, and hence the activation energy for chemical reactions on a large number of metal and alloy surfaces which function as the active sites in heterogeneous catalysts. ${ }^{19-25}$ The results show that alloying serves to modify the binding strength of intermediates, and hence moves the alloy to a new position along the linear BEP line (Figure 1a). In that sense, while alloying is a way to tune surface binding energies, this approach is still limited by BEP scaling; thus, there must still be a trade-off between low activation energy and weak binding. 

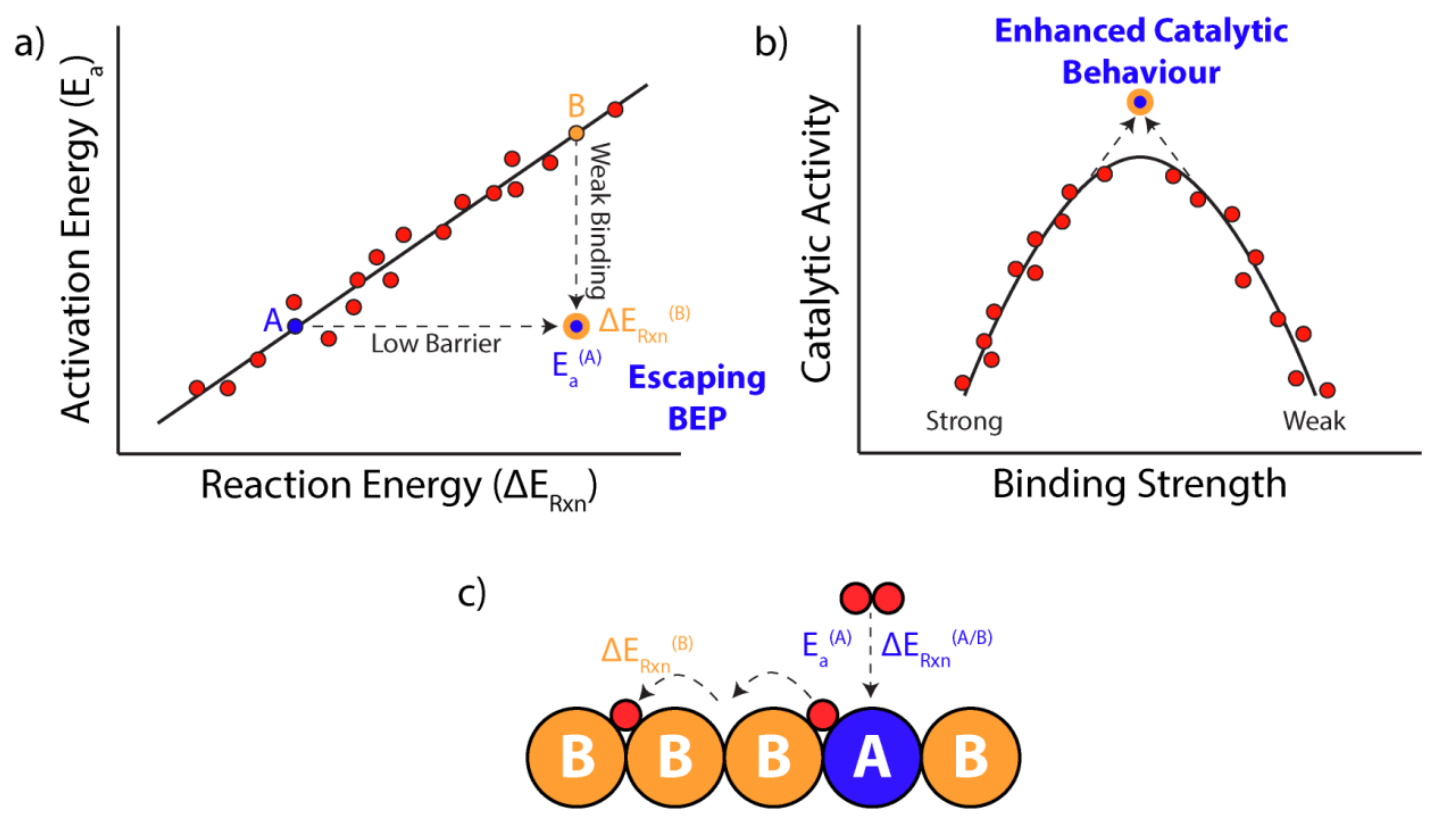

Figure 1: (a) Diagram showing a Brønsted-Evans-Polanyi relationship of activation energy as a linear function of reaction energy for a chemical conversion. A favorable deviation from linearity is shown (blue/orange point) in which the reaction activation energy is lowered in conjunction with more positive reaction energy (that is typically associated with weak binding); (b) a corresponding Sabatier volcano curve of the catalytic activity as function of binding strength showing an enhancement in the catalytic performance above what can be predicted by systems that are bound by linear scaling; and (c) a diagram of a single-atom alloy dissociating a molecule at a more reactive metal center $(A)$ with low activation energy $\left(E_{a}\right)$ and intermediate reaction energy $\left(\Delta \mathrm{E}_{\mathrm{Rxn}}\right)$ before subsequent spillover onto a multitude of weak-binding host metal atoms (B).

Undoubtedly though, the tunability offered by mixing different elements with control over stoichiometry allows catalysts to be made with greater activity, selectivity and stability than those derived from single metals. ${ }^{18-19,26-30}$ The superior properties of alloys are often discussed both in terms of ligand (electronic) and ensemble (geometric) effects, as well as the effect of strain. ${ }^{26,31-33}$ Although these effects are all interrelated, ligand effects refer to the change in catalytic properties due to electronic interactions between the two elements of a bimetallic alloy. Ensemble effects refer to the spatial distribution of atomic sites that bind reactants, leading e.g. to surface morphologies dominated by single atoms of one metal dispersed into another metal, or characterized by clusters/islands of various sizes on the surface. Some systems require larger such clusters of reactive atoms to catalyze chemical transformations, and are therefore halted when the active atom is dispersed throughout an inert lattice. Strain effects due to the epitaxial growth of layers of metals with different lattice constants can lead to variations in adsorbate binding and reactivity. Therefore, understanding the atomic-scale surface structure of metal alloys is a crucial step on the path towards designing optimal heterogeneous catalysts. 
In a related approach pioneered by Mavrikakis et al., calculations described so-called "nearsurface alloys", in which the electronic structure of a pure metal surface is modified through ligand and strain effects by a layer of a different element below. ${ }^{19}$ In this example, near-surface alloys follow BEP relationships for $\mathrm{H}_{2}$ activation, though the linear BEP fit is shifted in activation energy, whereby the intercept thereof is governed by the terminating surface metal. $\mathrm{Pt}$ and $\mathrm{Pd}$ pseudomorphic monolayer skins on transition metal hosts exhibit $\mathrm{H}$ adatom binding strength akin to that of pure noble metals, though much reduced transition state energies. Thus, near-surface alloys deviate from pure metal BEP scaling and may achieve catalytic performance that exceeds the limits of the Sabatier maximum (Figure 1, left) by combining low activation energy and weak binding. However, although promising it is unfortunate to note that, due to mixing, only a couple of examples of this synergy have been shown to be possible experimentally. ${ }^{19,22,30,34-37}$

From a different approach, an extreme example of utilizing the ensemble effect is to reduce the reactive site to a single atom. For example, if reactants dissociate at a more reactive atom A and intermediates bind at the surrounding less active element B (Figure 1c) then the BEP relationship breaks down (Figure 1a). ${ }^{38-41}$ Consequently, alloys that expose two elements at the surface should be able to escape linear scaling, and may be better catalysts than would have been predicted by BEP scaling. A key, recent example of this strategy in action is in the use of singleatom alloy (SAA) catalysts. SAAs are bimetallic alloys of catalytically active transition metals doped at low concentrations into inert coinage metal hosts, such that the dopant disperses in the form of individual, isolated atoms in the surface layer of the host lattice. Dispersion of the more reactive catalytic metal in SAAs gives rise to well defined active sites that facilitate substrate dissociation prior to intermediate binding at shared host-dopant sites and subsequent, entropically driven spillover onto a multitude of weak binding host metal sites. In this way, SAAs hold the potential to escape the constraints of the BEP relationship and can therefore exhibit enhanced catalytic performance (Figure 1).

In the remainder of this Perspective we will discuss some recent examples of experimental and simulated studies on SAAs, along with the opportunities they offer for breaking linear scaling. We should also note that by its very nature, this is a brief perspective of the SAA field focusing primarily on the work that the authors have been involved in. We do not intend for this to be a comprehensive review. For complementary literature on breaking linear scaling in a number of other systems the interested reader can consult Refs 42-48.

An early example of the SAA approach involved the dissociation of molecular $\mathrm{H}_{2}$ on a Pt/Cu SAA surface. ${ }^{49-53}$ This system breaks linear scaling because the transition state for dissociation lies above the $\mathrm{Pt}$ atom, whereas the binding sites of the two $\mathrm{H}$ atoms are three-fold hollow sites consisting of one $\mathrm{Pt}$ and two $\mathrm{Cu}$ atoms. ${ }^{53}$ In simple terms, efficient $\mathrm{H}_{2}$ activation only requires one $\mathrm{Pt}$ atom, and the weaker $\mathrm{H}$ atom binding can be understood by the three-fold binding site being only partially bonded to the strong binding Pt atom but also partially bonded to two weak binding $\mathrm{Cu}$ metal atoms. ${ }^{53}$ This is shown below in Figure 2. 


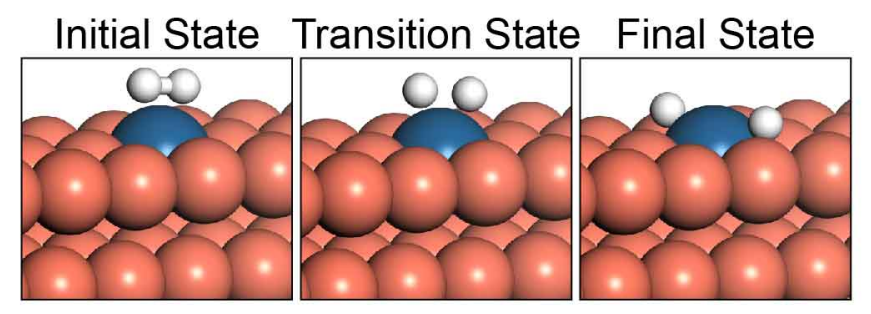

Figure 2: DFT calculated initial, transition and final state positions for $\mathrm{H}_{2}$ dissociation on a $\mathrm{Pt} / \mathrm{Cu}$ SAA surface..$^{53}$ It can be seen from the figure that in the initial and transition states the hydrogen molecule bonds exclusively to the $\mathrm{Pt}$ atom (blue), whereas in the final state the $\mathrm{H}$ atoms interact with the $\mathrm{Pt}$ atom and $\mathrm{Cu}$ atoms (orange). It is the different bonding contributions from each metal to the transition and final states that lead to initial deviations from the traditional BEP trend.

Experiments on the $\mathrm{Pt} / \mathrm{Cu}(111)$ SAA surface revealed that the $\mathrm{H}_{2}$ desorption peak maximum $(230 \mathrm{~K})$ was much lower than that expected for $\mathrm{H}_{2}$ desorption from $\mathrm{Cu}(111)(310 \mathrm{~K})$ or $\mathrm{Pt}(111)$ $(300 \mathrm{~K}){ }^{49-52}$ This effect demonstrates that individual, isolated $\mathrm{Pt}$ atoms dissociate $\mathrm{H}_{2}$ at low temperature and, as would be expected from microscopic reversibility, serve as low-barrier exit routes for $\mathrm{H}_{2}$ during the desorption process. ${ }^{49-52}$ In comparison, desorption of $\mathrm{H}_{2}$ from $\mathrm{Cu}(111)$ occurs at $\sim 310 \mathrm{~K}$ because of a large recombination barrier and from $\mathrm{Pt}(111)$ at $\sim 300 \mathrm{~K}$ due to strong binding. Our TPD data revealed that single $\mathrm{Pt}$ atoms in the $\mathrm{Cu}(111)$ surface lowered the activation barrier to $\mathrm{H}_{2}$ dissociation but also bind $\mathrm{H}$ weakly, thereby breaking linear scaling as illustrated in Figure 1a. Figure 3 shows the energetics for the process. Hence, alloying at the single atom limit can circumvent the compromise between low activation barriers and weak binding, which was discussed earlier in the context of pure metals.

Temperature programmed reaction measurements were also used to demonstrate that PtCu SAAs can act as very selective model catalysts for the industrially relevant hydrogenation of olefins. ${ }^{50}$ In particular, the selective hydrogenation of butadiene to butene is industrially important, as it serves to increase the purity of alkene feedstocks without reducing their overall concentration. The mode of action in model studies involves the facile dissociation of hydrogen on individual $\mathrm{Pt}$ atoms and the subsequent spillover of $\mathrm{H}$ atoms onto the $\mathrm{Cu}(111)$ surface. The selective hydrogenation takes place on the bare $\mathrm{Cu}(111)$ surface, where the $\mathrm{H}$ atoms are weakly bound. In marked contrast to the selective hydrogenation chemistry on SAAs, the hydrogenation of butadiene on 0.3 monolayer Pt was found to be accompanied by extensive decomposition and dramatically lower hydrogenation selectivity, due to extended Pt sites that bind adsorbates more strongly and break $\mathrm{C}-\mathrm{C}$ bonds, leading to unselective chemistry. ${ }^{49-52}$ 

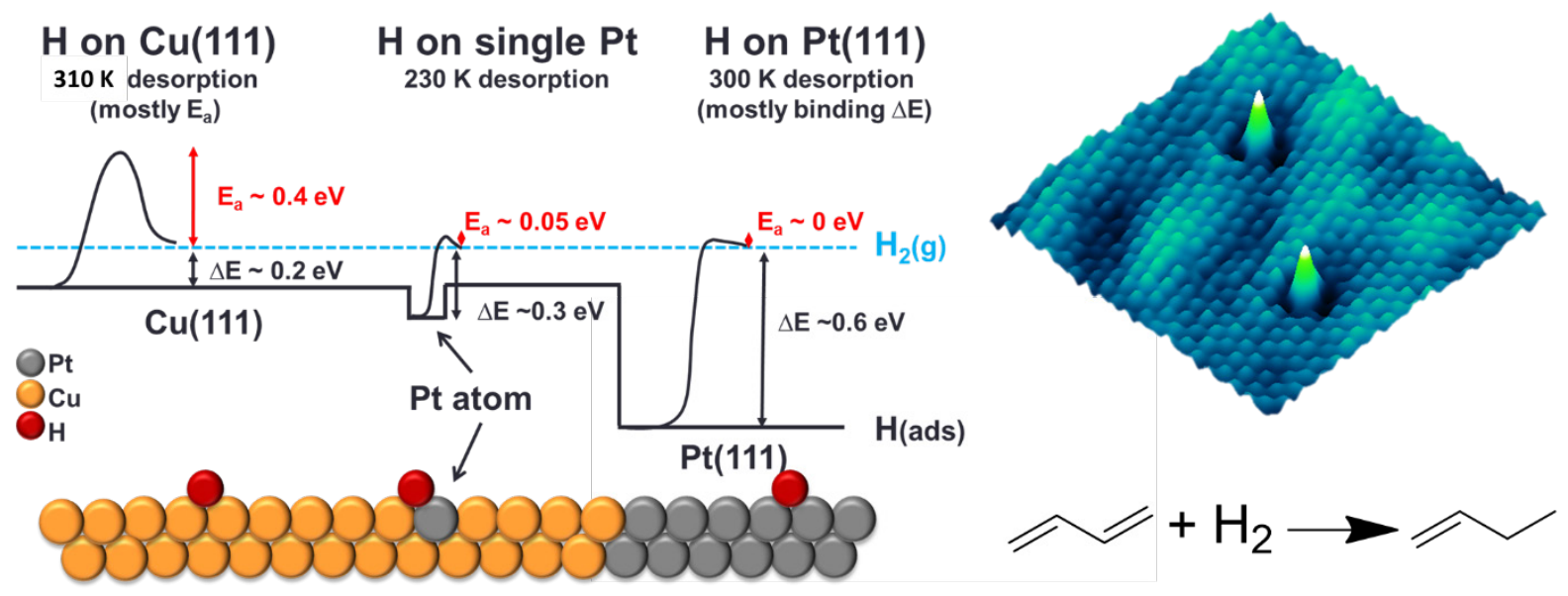

Figure 3. Individual $\mathrm{Pt}$ atoms convert the surface of $\mathrm{Cu}$ into a highly selective hydrogenation catalyst for the industrially relevant hydrogenation of butadiene to butenes. ${ }^{50}$ The schematic illustrates how $\mathrm{Cu}$ binds $\mathrm{H}$ atoms weakly but has a high barrier for $\mathrm{H}_{2}$ dissociation (left). Pure $\mathrm{Pt}$ on the other hand has almost no barrier but binds $\mathrm{H}$ atoms strongly (right). However, atomically dispersed $\mathrm{Pt}$ offers a small $\mathrm{H}_{2}$ dissociation barrier, the possibility of $\mathrm{H}$ spillover and most importantly, high catalytic selectivity due to weak binding to $\mathrm{Cu}$. The upper right image shows a $3 \mathrm{D}$ rendering of an atomically resolved STM image of two Pt atoms in a $\mathrm{Cu}(111)$ SAA surface.

Given that selective hydrogenations are ideally run at low temperatures at which $\mathrm{H}_{2}$ dissociation can be rate-limiting, this property of low $\mathrm{H}_{2}$ dissociation barriers and weak binding of intermediates, realized using the techniques of surface science, is attractive in terms of efficient catalysis. Informed by surface chemistry and microscopy studies, a number of different research groups have developed a new generation of $\mathrm{PdCu}, \mathrm{PdAu}, \mathrm{PdAg}, \mathrm{RhAu}$ and PtCu SAA nanoparticle catalysts for the selective hydrogenation of acetylene, phenylacetylene, styrene, hexyne and butadiene under realistic reaction conditions as well as Ullmann coupling. ${ }^{50,54-64}$ At low loadings, in situ extended X-ray absorption fine structure and aberration-corrected high angle annular dark field scanning transmission electron microscopy were used to show that $\mathrm{Pt}$ exists as individual, isolated atoms substituted into the $\mathrm{Cu}$ NP surface both before and after reaction. Nominal amounts of $\mathrm{Pt}(2$ at. \%) in $\mathrm{Cu}$ nanoparticle catalysts were found to exhibit high activity and selectivity for butadiene hydrogenation to butene under relatively mild conditions. ${ }^{50}$ This combined model system/NP catalyst strategy is proving to be a powerful approach in the design of new alloy catalysts. This approach is especially useful for highly dilute single-site systems, in which identification of the active sites and their chemistry is very challenging. Furthermore, this work reveals that in addition to their promising selective hydrogenation properties, SAAs provide the ultimate limit for the efficient use of costly catalytic elements like Pt.

Very recently, this combined approach to SAA catalyst design has been shown to work well for reactions rate limited by $\mathrm{C}-\mathrm{H}$ activation. ${ }^{65}$ The current availability of shale gas has created an 
urgent demand for heterogeneous catalysts that are both active towards $\mathrm{C}-\mathrm{H}$ activation and stable. PtCu SAAs activate $\mathrm{C}-\mathrm{H}$ bonds with significantly improved activity over $\mathrm{Cu}$, while avoiding coking that occurs on catalysts with extended Pt ensembles. In fact, these ultra-dilute $\mathrm{PtCu}$ alloy nanoparticle catalysts exhibited reaction temperatures $300^{\circ} \mathrm{C}$ lower than $\mathrm{Cu}$ under realistic operating conditions, as shown by our experiments on the non-oxidative dehydrogenation of butane to butene over $\mathrm{Pt}_{0.01} \mathrm{Cu}-\mathrm{SAA} .{ }^{65}$ Moreover, the reactivity was stable for at least 52 hours at $400^{\circ} \mathrm{C}$, and only minimal carbon deposition was observed on $\mathrm{Pt}_{0.01} \mathrm{Cu}-$ SAA compared to Pt-NP. On the theory side, DFT calculations revealed that the activation energies for $\mathrm{C}-\mathrm{H}$ bond scissions on $\mathrm{Cu}(111)$ are significantly lowered by the incorporation of a single surface $\mathrm{Pt}$ atom. $\mathrm{Pt} / \mathrm{Cu}(111)$ SAAs have $\mathrm{C}-\mathrm{H}$ activation properties intermediate to pure $\mathrm{Pt}(111)$ and $\mathrm{Cu}(111)$, though the dilution of $\mathrm{Pt}$ to the single-atom limit reduces the chemisorption strength of $\mathrm{CH}_{\mathrm{x}}$ species notably compared to pure $\mathrm{Pt}(111)$ and closer to that on $\mathrm{Cu}(111){ }^{65}$ Finally as shown by low temperature STM experiments, $\mathrm{CH}_{\mathrm{x}}$ fragments spillover from the single Pt atoms onto facets of pure $\mathrm{Cu}(111)$, thereby further lowering their adsorption energy. ${ }^{65}$ Thus, this $\mathrm{PtCu}$ SAA system combines low activation energies with weak adsorption, contrary to what is suggested by pure transition metal BEP scaling. The energy landscape for successive $\mathrm{C}-\mathrm{H}$ scissions from $\mathrm{CH}_{4}$ (g) is uphill on $\mathrm{Pt} / \mathrm{Cu}(111) \mathrm{SAA}$ and $\mathrm{Cu}(111)$ which helps to prevent the formation of carbon deposits on the surface. This is the strongest evidence to date that SAAs can be translated from surface science UHV investigations and computational DFT studies to harsh industrially relevant reaction conditions. ${ }^{65}$

While the above examples indicate that SAAs: i) escape linear-scaling; ii) have favorable energetics for both hydrogenation and dehydrogenation; and iii) can be employed in real catalysts operating stably under realistic reaction conditions, only a handful of systems have so far been explored, with the experimental development of each SAA taking many years to complete. ${ }^{34,49-52,54-56,58-83}$ Therefore, the discovery of metal-metal combinations that exhibit these attributes, as well as determining applicable chemistries on a reasonable timescale, remain non-trivial tasks. Generally, the majority of heterogeneous catalytic materials are discovered by trial-and-error methods, though this is both costly and time-consuming. However, unlike complex multicomponent heterogeneous catalysts, consisting of metal nanoparticles with their many shapes, sizes, dopants, promoters, interactions with the support etc., the design of SAA catalysts from first principles with state-of-the-art theoretical modelling is indeed tractable. Modelling SAAs at the molecular level before bridging length scales to those of real catalysts will develop our fundamental understanding of the physicochemical phenomena governing the excellent performance of SAAs. Thus, we present in the next section a summary of recent pivotal studies that have utilized theory and simulation to provide a roadmap for the design, development and application of SAAs in heterogeneous catalysis.

Early in the development of SAAs, simulation, particularly with DFT, had been employed as a tool to explain experimentally observed phenomena. Though the results of the DFT calculations depend on the exchange-correlation functional used, and quantitatively one should not put too much weight on the precise numbers obtained, DFT (with standard generalized-gradient approximation functionals) has proven to be very useful in understanding trends in heterogeneous catalysis and indeed in rationalizing experimental catalytic performance of SAAs. 
For example works by Luo et al., Ramos et al. and Yang et al., use DFT calculate kinetic barriers for $\mathrm{H}_{2}$ activation that are consistent with the facile low temperature dissociative adsorption observed in experiment, as well as quantifying $\mathrm{H}$ adatom spillover and showing that subsequent selective hydrogenation can occur on facets of pure host material. ${ }^{72-73,84-89}$ DFT has also been used to explain how SAAs can exhibit combined low temperature $\mathrm{C}-\mathrm{H}$ activation and coke resistance $^{65}$ (see section 3), to justify why SAAs have excellent tolerance to poisoning by $\mathrm{CO},{ }^{90}$ to aid in SAA surface characterization, ${ }^{75}$ and to rationalize their ability to perform dry, nonoxidative dehydrogenation of alcohols. ${ }^{79}$ Most recently, simulation using DFT has become more exploratory. ${ }^{53,90-92}$ Progress in applying theory and simulation to SAA systems has now reached a pivotal point where it is not only being used to explain experimental findings, but to make predictions. Thus, in the remainder of this Perspective, we will give a summary of key recent studies that provide insight into the structural stability, electronic structure and chemical reactivity of numerous SAAs yet to be experimentally synthesized and tested. Together, these findings form a fundamental guide for the development of SAAs for catalytic applications.

In terms of composition, there is a multitude of metal-metal combinations that might make interesting bimetallic systems. Unfortunately, not all of these blends of metals will favorably form SAAs or indeed alloy structures in general. A number of studies have used DFT to elucidate segregation and surface mixing enthalpies of binary metal alloys, ${ }^{93-94}$ though a more recent study focused particularly on highly dilute binary alloys formed of coinage metal slabs that are doped with one, two and three transition metal atoms..$^{90}$ This study explored the thermodynamic stability of group 8,9 and 10 catalytic metals doped at high dilution in coinage metal lattices and described the preference for single atoms to segregate into the bulk or to the surface in addition to whether these atoms prefer to disperse or to aggregate. ${ }^{90}$ 


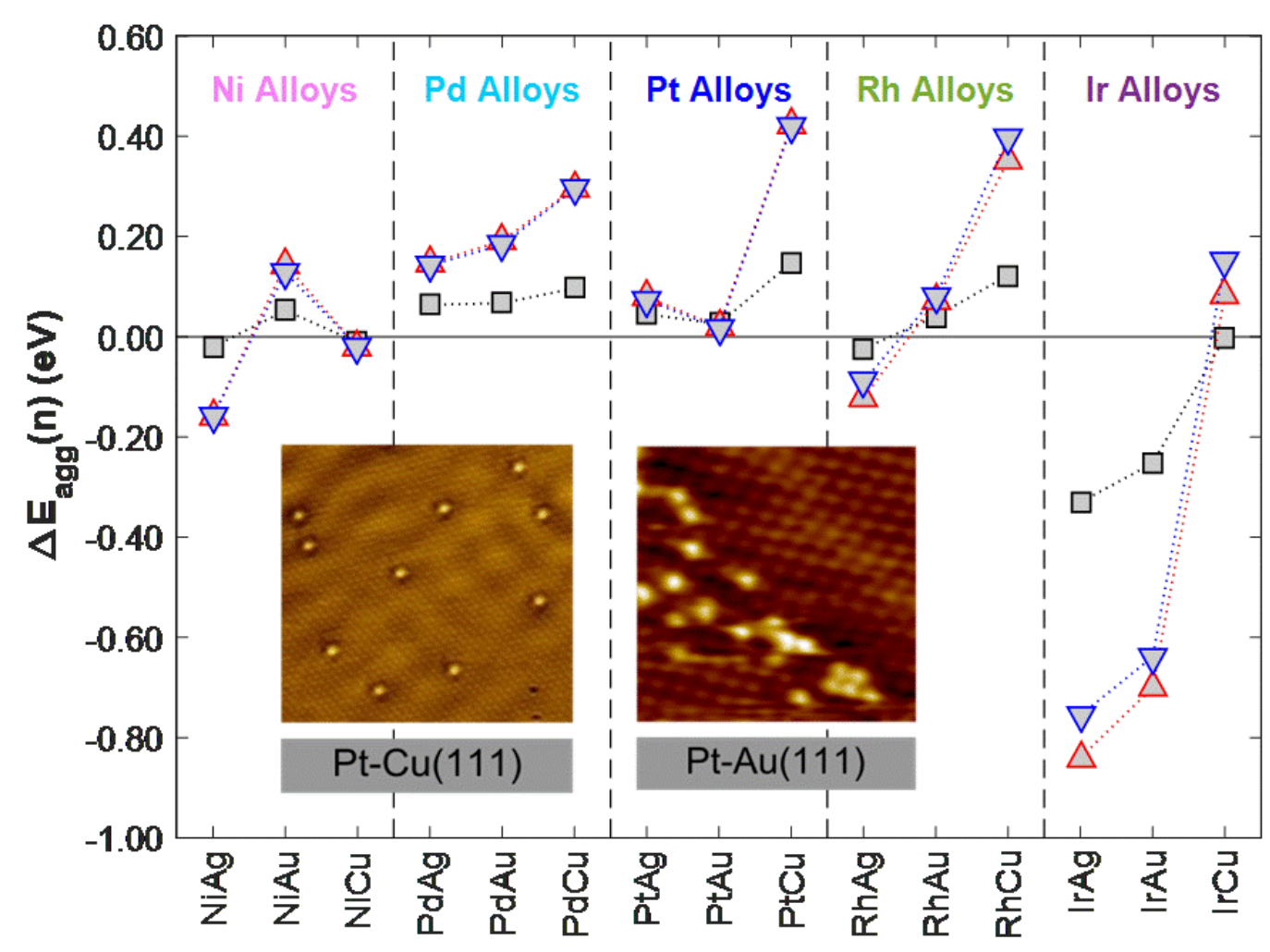

Figure 4: The energy of aggregation $\Delta E_{a g g}(n)$ relative to the SAA phase for the clustering of group 10 dopant atoms in the (111) surface of group 11 host metals into dimers (black squares) and trimers where dopant atoms surround fcc (red up-triangles) and hcp (blue, down-triangles) sites. Insets show examples of when aggregation is not $(\mathrm{PtCu})$ versus when it is $(\mathrm{PtAu})$ favoured. Values of $\Delta E_{a g g}(n)$ that are negative correspond to a preference for surface clustering, whereas positive values correspond to a preference for dopant atom dispersion to the SAA structure; $\Delta E_{\text {agg }}(n)=E_{\text {Tot }}(n)+(n-1) \cdot E_{\text {Tot }}($ host $)-n \cdot E_{\text {Tot }}(S A A)$, where $E_{\text {Tot }}(n)$ and $E_{\text {Tot }}($ host $)$ are the DFT total energies of an alloy surface with a cluster of $n$ dopant atoms and the pure host material, respectively. Adapted from Ref. ${ }^{90}$.

Although the actual values of the DFT-computed energetics cannot be regarded as exact, the trends obtained reveal that for platinum group metal dopants at high dilution, there are many systems with a strong enthalpic preference for the formation of SAAs, as compared to structures with aggregated ensembles (Figure 4). Those surfaces with additional enthalpic driving force favoring the SAA structure include Ni-, Pd-, Pt-, Rh- and Ir-doped $\mathrm{Cu}(111)$ alloys as well as Pd-, Pt-, Ni- and Rh-doped Au(111) and Pd-, Pt-doped Ag(111). Notably, there is also a large, temperature dependent entropic driving force for single-atom dispersion thanks to the high multiplicity of host metal sites, which can only serve to increase the number of systems with a preference for dopant atom isolation.

The DFT calculations suggest that Pt- and Pd-doped $\mathrm{Cu}(111)$ are the only SAAs where the single atom is enthalpically more stable in the surface layer, rather than segregating into the bulk. 
Notably, due to the high number of bulk metal lattice sites compared to that on the surface, there is an entropic driving force for segregation into the bulk. These results are somewhat contradictory to experimental evidence that demonstrates that $\mathrm{Ni} / \mathrm{Au}, \mathrm{Ni} / \mathrm{Cu}$ and $\mathrm{Pd} / \mathrm{Au}$ also form stable extended surface and nanoparticle SAAs. Interestingly, further DFT calculations of the stability of these alloys suggest that the heats of adsorption of adspecies present during a reaction, such as $\mathrm{CO}$, can overturn the enthalpic preference for dopant atom segregation into the bulk. ${ }^{90}$ This situation is perhaps more representative of true ambient operating conditions. Thus, assuming segregation is less likely under ambient reaction conditions, as has been shown experimentally $^{50,65}$ and predicted with simulation by Yang et al. ${ }^{84-85}$ for both hydrogenation and dehydrogenation reactions, and that there is a timescale separation between segregation and surface adsorption, the plot of aggregation energies given in Figure 4 can be used as guide that narrows the SAA design-space down to those systems most likely to be viable, thereby maximizing efficiency from an experimental development standpoint.

DFT studies that explicitly account for adsorbates and their effect on the surface structure suggest that strong binding or multi-centered adsorbates can be used to tune the surface structure of highly dilute alloys. ${ }^{84-85,90}$ For example $\mathrm{CO}$ adsorption is preferential on the dopant top site of SAA surfaces, though for aggregates of two or three atoms, binding may be strongest in bridge and hollow sites. ${ }^{90}$ Therefore, by tuning the $\mathrm{CO}$ partial pressure during synthesis, the production of well-defined catalytic architectures (including dopant atom dimers and trimers) may be feasible. Tuning the ensemble size with well-defined multimer dispersity may prove to be a useful extension, as such surfaces are likely to exhibit comparably high selectivities to SAAs. This approach could also unlock the potential to dissociate molecules such as molecular oxygen, which Oğuz et al. have reported to be more difficult on single atoms as compared to dimers. ${ }^{95}$

In addition to elucidating the SAA structures whose formation is favorable, theory and simulation can be used to identify chemical conversions that can be catalyzed by these surfaces, ${ }^{53}$ though to do so, it is instructive to analyze their electronic structure. In particular, Thirumalai et al. have shown that the atom-projected d-band density of states (PDOS) graphs of SAA surfaces, generally exhibit a sharp peak of high population over a narrow energy span close to the Fermi level. ${ }^{92}$ This feature in the PDOS is the result of a charge localization and ineffective charge mixing between the two metals in the alloy. ${ }^{92}$ The peak is unusually sharp, even for an alloy system, and in fact is more akin to that found in the PDOS of an isolated gas phase atom, rather than an extended metallic surface. ${ }^{92}$ This atom-like PDOS feature is thought to be responsible for the high surface reactivity of SAA dopant atoms.

Adsorption energy screening studies employing a library of catalytically relevant species on SAAs, highlight that adsorbates generally bind more weakly on SAA surfaces than when compared to the monometallic catalytic metals, albeit more strongly than when compared to the coinage metals. ${ }^{53,92}$ In certain cases, for example with some Ni-, Rh- and Ir-doped SAAs, fragments exhibit more exothermic adsorption to the isolated dopant compared to pure $\mathrm{Ni}, \mathrm{Rh}$ and Ir, respectively. ${ }^{53}$ For example, a RhAg SAA is predicted to bind CO more strongly than pure $\mathrm{Rh}(111)$ itself. ${ }^{53,90}$ Interestingly for SAAs, the host-like or dopant-like strength of the bonding is not generally discerned through some linear combination of pure-host or pure-dopant 
adsorption energies, ${ }^{96-98}$ nor do these surfaces adhere to the d-band adsorption model. ${ }^{53,92}$ This makes SAA catalysts novel and exciting; by not following the scaling models of other pure and alloy transition metal surfaces, SAAs can offer unique adsorption properties that, when understood, can be employed in the design of superior catalysts. ${ }^{53}$

The high dilution of isolated dopant atoms in SAA surfaces gives rise to several unique adsorption site types with varying properties. ${ }^{53}$ Adsorption to the 1-fold dopant top site can be loosely thought of as bond formation with the dopant atom only. This is distinct from binding to the bridge or hollow sites, where there is shared bonding between the dopant atom and two or three surface host atoms, respectively. The ineffective charge mixing between the dopant and host metal atoms in SAAs is responsible for this variation in reactivity between sites, where the extent of the differences will depend on the SAA composition, in addition to the nature of the site. $^{53}$

Variable chemical reactivity between different site types on the same SAA surface has interesting consequences on the BEP relationship. For several simple bond scission reactions $(\mathrm{H}-$ $\mathrm{H}, \mathrm{C}-\mathrm{H}, \mathrm{N}-\mathrm{H}, \mathrm{C}=\mathrm{O}$ and $\mathrm{O}-\mathrm{H})$, DFT calculations show that when the initial, transition and final state geometries are bound to different site types, they do not have the same bonding contributions from the dopant and host; consequently, the activation and reaction energies for the dissociation are decoupled. This is well demonstrated in the case of $\mathrm{H}_{2}$ bond activation. As discussed earlier in Section 2, the transition state is located directly over the dopant top site, whereas the final state $\mathrm{H}$ adatoms dissociate into shared dopant-host hollow sites. The BEP plot in Figure 5a shows clearly how the SAAs combine dopant-like activation energy with intermediate adsorption strength, allowing the corresponding data points (red) to deviate significantly from the BEP trendline prescribed by the pure transition metals (blue). This kind of deviation from pure transition metal BEP scaling is also calculated for catalytic metal surface terminated alloy overlayers and near-surface alloys. ${ }^{19}$ However, the notable difference between overlayer alloys and SAAs is in their surface structures; ideal overlayer alloys have chemically homogeneous surfaces, however SAAs have chemically heterogeneous surfaces due to a low number of dopant atom with a high degree of dispersion. Thus, on SAAs, further deviations from the BEP relationship can occur as a result of spillover (Figure 5a (green)); the high degree of dopant atom dispersion and high number of host metal sites will promote the entropic spillover of dissociated adsorbates onto facets of the noble metal, consequently reducing the binding energy of adspecies. Thus, SAAs combine platinum group metal-like activation energy with noble metal-like binding energy which will inevitably result in enhanced catalytic performance (Figure 1). 

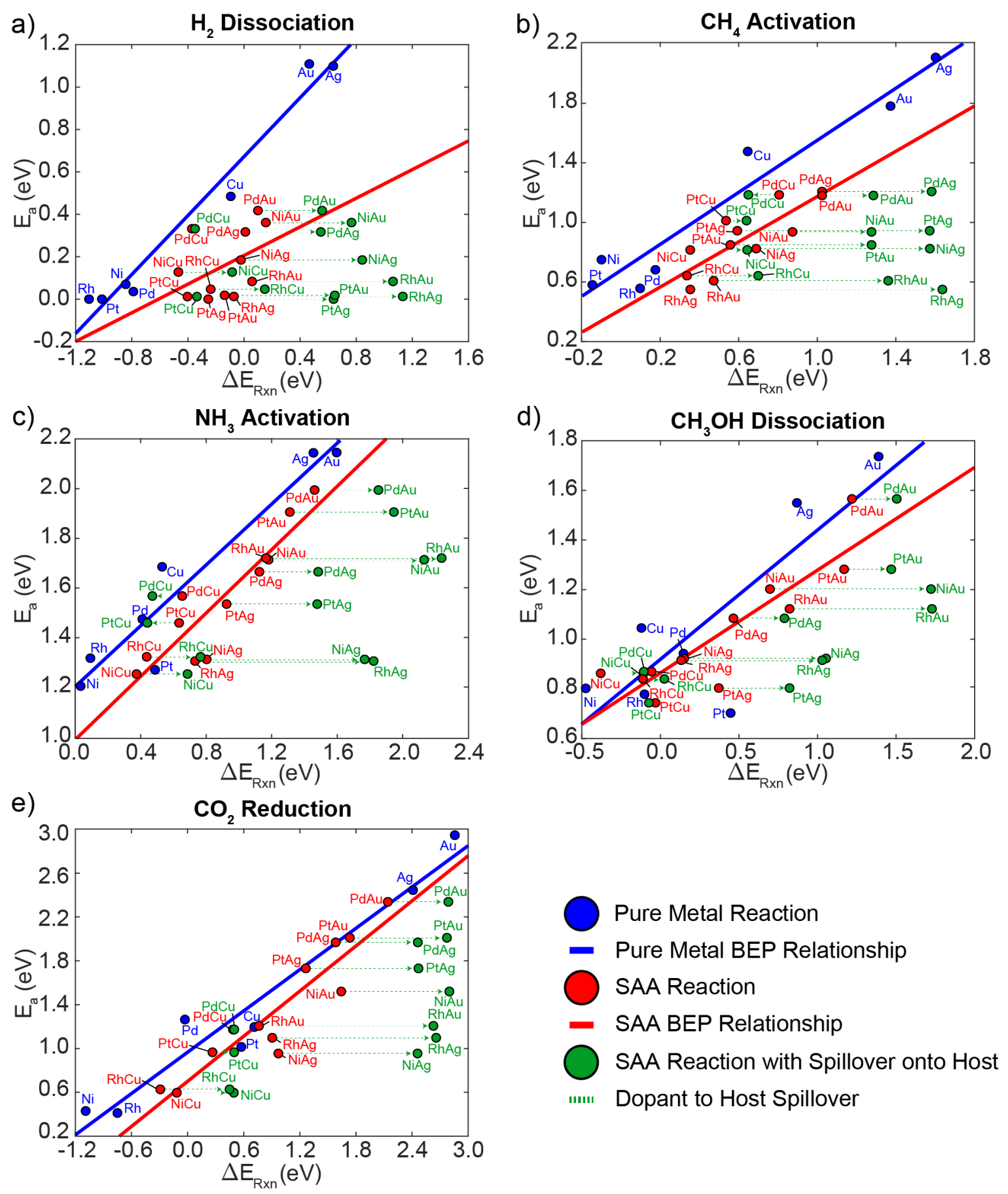

Figure 5. Brønsted-Evans-Polanyi plots of the activation energy $\left(\mathrm{E}_{\mathrm{a}}\right)$ as a function of reaction energy $\left(\Delta \mathrm{E}_{\mathrm{Rxn}}\right)$ for several key catalytic bond dissociations $(\mathrm{H}-\mathrm{H}, \mathrm{C}-\mathrm{H}, \mathrm{N}-\mathrm{H}, \mathrm{C}=\mathrm{O}$ and $\mathrm{O}-\mathrm{H})$. Reactions are shown for i) pure metals (blue); ii) on SAAs where dissociation and binding occurs at/proximal to the single dopant atom (red); and iii) on SAAs where dissociation occurs at/proximal to the single dopant atom before the dissociated species spill over onto the host material (green). Adapted from Ref. 53. See supporting information for tables of the data." 
A wider screening study of several catalytically relevant bond scission reactions shows that SAA BEP trendlines consistently fall below those of pure transition metals for each of the chemistries considered (Figure 5). ${ }^{53,}$ In many cases, SAAs exhibit small variations in activation barrier compared to the pure transition metals but much larger endothermic changes in the reaction energy which shifts the BEP trendline to the right of the plots in Figure 5. Generally speaking $\mathrm{H}_{2}, \mathrm{CH}_{4}$ and $\mathrm{NH}_{3}$ bond activations proceed via transition states located on top of the dopant metal atom and therefore the transition state stabilization due to the dopant atom is maximized. ${ }^{53}$ In the dissociated state, both site competition between fragments and a reduction in the valency of these surface species promote chemisorption in shared dopant-host sites where the relative bonding contribution from the dopant metal is less than in the transition state, therefore shifting the BEP line to the right (Figure 5). ${ }^{53}$ This is less pronounced in the cases of $\mathrm{CH}_{3} \mathrm{OH}$ dissociation and $\mathrm{CO}_{2}$ reduction as their transition states are most frequently located at shared dopant-host sites. ${ }^{53}$

Furthermore, when considering spillover, the deviations from the BEP relationship are large and suggest that SAAs can exhibit facile bond dissociation akin to pure platinum group metals, though will also exhibit noble metal-like reaction selectivity for numerous reactions. ${ }^{53}$ The extent of the total deviations from the BEP relationship will largely depend on the possibility of substrate spillover. There are many weak binding host metal sites compared to dopant metal sites which create a large entropic driving force to overcome the binding energy difference between the dopant and host sites. Additionally, post-dissociation binding to the SAA dopant atom is weak compared to the binding on the pure dopant surface, making the combined reaction and spillover step less endothermic on the SAA than on the pure dopant metal.

Figure 5 further shows that the extent of any deviations from the transition metal BEP relationship is dependent on the reaction. As alluded to in the case of $\mathrm{H}_{2}$ dissociation, the relative positions of the initial, transition and final states are key; the largest initial deviations (see red dots in Figure 5) are encountered when the transition state is located at the dopant top site and the final state is in shared or even host-only sites. Generally, each molecule studied in Figure 5 has characteristic initial, transition and final state geometries that are irrespective of the SAA composition. Instead, the relative bonding contributions to each metal atom vary primarily with substrate rather than SAA surface suggesting that the degree to which reactions deviate from transition metal BEP relations will depend on adsorbate composition, geometry and therefore bonding atom valency. Further deviations will then depend on the balance between the binding energy difference between SAA adsorption and host metal adsorption sites, which will govern the potential for spillover. Any deviations from the linear BEP relationships will have attractive consequences for catalysis, as elementary events within the same overall mechanism of a chemical transformation, may become decoupled from one another. This was observed, for example, in the case of facile $\mathrm{H}_{2}$ activation at the dopant metal and selective hydrogenation on the host metal post-dissociation.

The propensity for spillover of adspecies from the dopant atom to facets of the host material may be quantified through a simple free energy analysis. Assuming the adsorbate overlayer is at quasi-equilibrium, the relative coverage of an adsorbate on the dopant and host metal sites is a 
function of the binding energy and chemical potential of this species thereon. Therefore, the relative coverage may be predicted using Fermi-Dirac statistics (see supporting information) with binding energies derived from DFT. Thus, one may estimate a priori whether spillover for a given species will occur without the need for a detailed kinetic analysis. In non-ideal cases, there will be complex surface lateral interactions that influence the spillover and may require more complicated treatment using approximations or kinetic Monte Carlo simulation.

Thanks to these theoretical developments, a basic understanding of SAA stability, electronic structure and chemical reactivity has emerged. This knowledge serves as a guide to theoreticians and experimentalists alike, who may wish to further the study of these exciting materials. Broad screening studies convey which metal-metal combinations are the most promising candidates for experimental synthesis, which chemistries SAAs are likely to exhibit superior catalytic properties towards (as compared to monometallic analogues), and for those reactions, which SAAs are expected to perform the best. When combined with fundamental surface science and nanoparticle experiments, these calculations will facilitate the design and development of SAA materials with fine-tuned catalytic properties.

We hope that through this combined approach, the use of SAAs will be further expanded beyond the chemistries we have considered in this perspective. Of course, the scope here is very much tailored to applications within industrially relevant thermal heterogeneous catalytic systems, however, we recognize that areas such as organic synthesis and electrocatalysis ${ }^{80,91}$ may benefit greatly from properties such as atom economy, high reaction selectivity due to tandem sites, resilience to CO poisoning, and lack of coking offered by SAAs.

The use of SAAs in catalysis is a simple yet demonstrably powerful strategy towards the rational design of catalysts with superior activity and selectivity compared to pure metals or other types of alloys. Theory and simulation in conjunction with experiment show that their special properties cannot be captured well by established concepts, in particular linear scaling relations. DFT studies reveal that SAAs do not follow the d-band adsorption model that is adhered to by pure metals and many other alloy systems. ${ }^{92}$ Moreover, dramatically varying electronic properties across the surface of SAAs results in decoupling of adsorption energies between species with different valencies and site binding preferences. Interestingly, this also applies to transition and stable state geometries for numerous bond dissociation reactions such that SAAs combine weak binding and low activation, thereby escaping traditional BEP relationships. This creates new opportunities for SAAs to catalyze reactions with superior performance, for example $\mathrm{Pt} / \mathrm{Cu}$ can carry out facile $\mathrm{H}_{2}$ dissociation in conjunction with highly selective hydrogenation and can activate $\mathrm{C}-\mathrm{H}$ bonds at low temperature without coke formation; in both cases, bond activations on $\mathrm{Pt} / \mathrm{Cu}$ deviate from the $\mathrm{BEP}$ relationship followed by pure $\mathrm{Pt}$ and pure $\mathrm{Cu}$, yet combine their most desirable properties. The synergistic approach of using combined fundamental surface studies with simulation, has proven fruitful in rationalizing observations about the excellent catalytic behavior of SAAs on the few systems that have been developed experimentally. Perhaps most excitingly, the current frontier of the combined approach provides us with a platform for making predictions about the catalytic properties of SAAs and therefore designing catalysts that can be fine-tuned in terms of activity, selectivity and stability in a 
rational way. Immediate challenges for the field are to demonstrate spillover of intermediates in real catalysts and interrogate if real SAA catalysts are indeed bifunctional, as has been shown experimentally in the model systems. ${ }^{50,71}$ Finally, and mostly importantly, these simulation data on five reactions on 12 different SAA combinations serve as a guide for the development of many more SAA systems for a variety of different chemical reactions and we challenge the catalytic community to synthesize and test some off the most promising combinations, for example $\mathrm{RhCu}$ for $\mathrm{C}-\mathrm{H}$ activation chemistry. ${ }^{53,90}$

\section{Acknowledgements:}

E.C.H.S. thanks the Division of Chemical Sciences, Office of Basic Energy Sciences, CPIMS Program, U.S. Department of Energy, under Grant No. FG02-10ER16170 for the financial support of this work. M. T. D. is supported by the EPSRC Doctoral Prize Fellowship, grant reference number EP/N509577/1. A.M. is supported by the European Research Council (ERC) under the European Union's Seventh Framework Program (FP/2007-2013)/ERC Grant Agreement 616121 (HeteroIce project). The authors acknowledge the use of the UCL High Performance Computing Facilities (Legion@UCL, Grace@UCL and Thomas@UCL), and associated support services, in the completion of the computational part of this work. We are grateful to the UK Materials and Molecular Modelling Hub for computational resources, which is partially funded by EPSRC (EP/P020194/1).

\section{References:}

1. U.S. Department of Energy, Catalysis for Energy: Fundamental Science and Long-Term Impacts of the U. S. Department of Energy Basic Energy Science Catalysis Science Program. 2009.

2. Bell, A.; Gates, B.; Ray, D., Basic research needs: catalysis for energy. DOE Office of Basic Energy Sciences Workshop Report, August. 2007.

3. Bowker, M., The basis and applications of heterogeneous catalysis. Oxford Chemistry Primers 1998, 53 (1), ALL-ALL.

4. Chorkendorff, I.; Niemantsverdriet, J. W., Concepts of modern catalysis and kinetics. John Wiley \& Sons: 2017.

5. Pallassana, V.; Neurock, M., Electronic Factors Governing Ethylene Hydrogenation and Dehydrogenation Activity of Pseudomorphic PdML/Re(0001), PdML/Ru(0001), $\mathrm{Pd}(111)$, and PdML/Au(111) Surfaces. J. Catal. 2000, 191 (2), 301-317.

6. Liu, Z.-P.; Hu, P., General trends in $\mathrm{CO}$ dissociation on transition metal surfaces. J. Chem. Phys. 2001, 114 (19), 8244-8247.

7. Logadottir, A.; Rod, T. H.; Nørskov, J. K.; Hammer, B.; Dahl, S.; Jacobsen, C. J. H., The BrønstedEvans-Polanyi Relation and the Volcano Plot for Ammonia Synthesis over Transition Metal Catalysts. J. Catal. 2001, 197 (2), 229-231.

8. Jacobsen, C. J. H.; Dahl, S.; Clausen, B. S.; Bahn, S.; Logadottir, A.; Nørskov, J. K., Catalyst Design by Interpolation in the Periodic Table: Bimetallic Ammonia Synthesis Catalysts. J. Am. Chem. Soc. 2001, 123 (34), 8404-8405.

9. Michaelides, A.; Liu, Z. P.; Zhang, C. J.; Alavi, A.; King, D. A.; Hu, P., Identification of General Linear Relationships between Activation Energies and Enthalpy Changes for Dissociation Reactions at Surfaces. J. Am. Chem. Soc. 2003, 125 (13), 3704-3705. 
10. Abild-Pedersen, F.; Greeley, J.; Studt, F.; Rossmeisl, J.; Munter, T. R.; Moses, P. G.; Skúlason, E.; Bligaard, T.; Nørskov, J. K., Scaling Properties of Adsorption Energies for Hydrogen-Containing Molecules on Transition-Metal Surfaces. Phys. Rev. Lett. 2007, 99 (1), 016105.

11. Hammer, B.; Norskov, J. K., Why gold is the noblest of all the metals. Nature 1995, 376 (6537), 238-240.

12. Hammer, B.; Nørskov, J. K., Electronic factors determining the reactivity of metal surfaces. Surf. Sci. 1995, 343 (3), 211-220.

13. Xin, H.; Vojvodic, A.; Voss, J.; Nørskov, J. K.; Abild-Pedersen, F., Effects of d-band shape on the surface reactivity of transition-metal alloys. Phys. Rev. B 2014, 89 (11), 115114.

14. Norskov, J. K.; Bligaard, T.; Rossmeisl, J.; Christensen, C. H., Towards the computational design of solid catalysts. Nat Chem 2009, 1 (1), 37-46.

15. Bligaard, T.; Nørskov, J. K.; Dahl, S.; Matthiesen, J.; Christensen, C. H.; Sehested, J., The Brønsted-Evans-Polanyi relation and the volcano curve in heterogeneous catalysis. J. Catal. 2004, 224 (1), 206-217.

16. Sabatier, P., Hydrogénations et déshydrogénations par catalyse. Berichte der deutschen chemischen Gesellschaft 1911, 44 (3), 1984-2001.

17. Norskov, J. K.; Bligaard, T.; Hvolbaek, B.; Abild-Pedersen, F.; Chorkendorff, I.; Christensen, C. H., The nature of the active site in heterogeneous metal catalysis. Chem. Soc. Rev. 2008, 37 (10), 2163-2171. 18. Besenbacher, F.; Chorkendorff, I.; Clausen, B. S.; Hammer, B.; Molenbroek, A. M.; Nørskov, J. K.; Stensgaard, I., Design of a Surface Alloy Catalyst for Steam Reforming. Science 1998, 279 (5358), 19131915.

19. Greeley, J.; Mavrikakis, M., Alloy catalysts designed from first principles. Nat Mater 2004, 3 (11), 810-815.

20. Xu, Y.; Ruban, A. V.; Mavrikakis, M., Adsorption and Dissociation of O2 on Pt-Co and Pt-Fe Alloys. J. Am. Chem. Soc. 2004, 126 (14), 4717-4725.

21. Fajín, J. L. C.; Cordeiro, M. N. D. S.; Gomes, J. R. B., Water Dissociation on Bimetallic Surfaces: General Trends. J. Phys. Chem. C 2012, 116 (18), 10120-10128.

22. Greeley, J.; Mavrikakis, M., Near-surface alloys for hydrogen fuel cell applications. Catal. Today 2006, 111 (1-2), 52-58.

23. Greeley, J.; Nørskov, J. K.; Kibler, L. A.; El-Aziz, A. M.; Kolb, D. M., Hydrogen Evolution Over Bimetallic Systems: Understanding the Trends. ChemPhysChem 2006, 7 (5), 1032-1035.

24. Greeley, J.; Jaramillo, T. F.; Bonde, J.; Chorkendorff, I.; Norskov, J. K., Computational highthroughput screening of electrocatalytic materials for hydrogen evolution. Nat Mater 2006, 5 (11), 909913.

25. Hansgen, D. A.; Vlachos, D. G.; Chen, J. G., Using first principles to predict bimetallic catalysts for the ammonia decomposition reaction. Nat Chem 2010, 2 (6), 484-489.

26. Rodriguez, J. A., Physical and chemical properties of bimetallic surfaces. Surf. Sci. Rep. 1996, 24 (7), 223-287.

27. Greeley, J.; Nørskov, J. K., Large-scale, density functional theory-based screening of alloys for hydrogen evolution. Surf. Sci. 2007, 601 (6), 1590-1598.

28. Wittstock, A.; Zielasek, V.; Biener, J.; Friend, C. M.; Bäumer, M., Nanoporous Gold Catalysts for Selective Gas-Phase Oxidative Coupling of Methanol at Low Temperature. Science 2010, 327 (5963), 319-322.

29. Chopra, I. S.; Chaudhuri, S.; Veyan, J. F.; Chabal, Y. J., Turning aluminium into a noble-metal-like catalyst for low-temperature activation of molecular hydrogen. Nat Mater 2011, 10 (11), 884.

30. Knudsen, J.; Nilekar, A. U.; Vang, R. T.; Schnadt, J.; Kunkes, E. L.; Dumesic, J. A.; Mavrikakis, M.; Besenbacher, F., A Cu/Pt Near-Surface Alloy for Water-Gas Shift Catalysis. J. Am. Chem. Soc. 2007, 129 (20), 6485-6490. 
31. Liu, P.; Norskov, J. K., Ligand and ensemble effects in adsorption on alloy surfaces. PCCP 2001, 3 (17), 3814-3818.

32. Sakong, S.; Mosch, C.; Gro, CO adsorption on Cu-Pd alloy surfaces: ligand versus ensemble effects. PCCP 2007, 9 (18), 2216-2225.

33. Inderwildi, O. R.; Jenkins, S. J.; King, D. A., When adding an unreactive metal enhances catalytic activity: NOx decomposition over silver-rhodium bimetallic surfaces. Surf. Sci. 2007, 601 (17), L103L108.

34. Tierney, H. L.; Baber, A. E.; Sykes, E. C. H., Atomic-Scale Imaging and Electronic Structure Determination of Catalytic Sites on Pd/Cu Near Surface Alloys. J. Phys. Chem. C 2009, 113 (17), 72467250.

35. Christoph, R.; Werner, S.; Christian, W.; Simon, P.; Harald, L.; Michael, H.; Raoul, B.; Tulio, R.; Detre, T.; Axel, K. G.; Robert, S.; Norbert, M.; Dmitry, Z.; Günther, R.; Bernhard, K., SubsurfaceControlled $\mathrm{CO} 2$ Selectivity of PdZn Near-Surface Alloys in H2 Generation by Methanol Steam Reforming. Angew. Chem. Int. Ed. 2010, 49 (18), 3224-3227.

36. Henry, J. B.; Maljusch, A.; Huang, M.; Schuhmann, W.; Bondarenko, A. S., Thin-Film Cu-Pt(111) Near-Surface Alloys: Active Electrocatalysts for the Oxygen Reduction Reaction. ACS Catalysis 2012, 2 (7), 1457-1460.

37. Zhang, X.; Yu, S.; Zheng, W.; Liu, P., Stability of Pt near surface alloys under electrochemical conditions: a model study. PCCP 2014, 16 (31), 16615-16622.

38. Peterson, A. A.; Nørskov, J. K., Activity Descriptors for CO2 Electroreduction to Methane on Transition-Metal Catalysts. J. Phys. Chem. Lett. 2012, 3 (2), 251-258.

39. Yamada, Y.; Tsung, C.-K.; Huang, W.; Huo, Z.; Habas, S. E.; Soejima, T.; Aliaga, C. E.; Somorjai, G. A.; Yang, P., Nanocrystal bilayer for tandem catalysis. Nat Chem 2011, 3, 372.

40. Andersen, M.; Medford, A. J.; Nørskov, J. K.; Reuter, K., Analyzing the Case for Bifunctional Catalysis. Angew. Chem. 2016, 128 (17), 5296-5300.

41. Andersen, M.; Medford, A. J.; Nørskov, J. K.; Reuter, K., Scaling-Relation-Based Analysis of Bifunctional Catalysis: The Case for Homogeneous Bimetallic Alloys. ACS Catalysis 2017, 3960-3967.

42. Wang, P.; Chang, F.; Gao, W.; Guo, J.; Wu, G.; He, T.; Chen, P., Breaking scaling relations to achieve low-temperature ammonia synthesis through $\mathrm{LiH}$-mediated nitrogen transfer and hydrogenation. Nat Chem 2017, 9 (1), 64.

43. Gani, T. Z.; Kulik, H. J., Understanding and Breaking Scaling Relations in Single-Site Catalysis: Methane to Methanol Conversion by FeIV \D. ACS Catalysis 2018, 8 (2), 975-986.

44. Calle-Vallejo, F.; Krabbe, A.; García-Lastra, J. M., How covalence breaks adsorption-energy scaling relations and solvation restores them. Chem. Sci. 2017, 8 (1), 124-130.

45. Xu, Y.; Fan, C.; Zhu, Y.-A.; Li, P.; Zhou, X.-G.; Chen, D.; Yuan, W.-K., Effect of Ag on the control of $\mathrm{Ni}$-catalyzed carbon formation: A density functional theory study. Catal. Today 2012, 186 (1), 54-62.

46. Montemore, M. M.; Medlin, J. W., Scaling relations between adsorption energies for computational screening and design of catalysts. Catal. Sci. Technol. 2014, 4 (11), 3748-3761.

47. Greeley, J., Theoretical Heterogeneous Catalysis: Scaling Relationships and Computational Catalyst Design. Annu. Rev. Chem. Biomol. 2016, 7 (1), 605-635.

48. $\quad \mathrm{Li}, \mathrm{Y}$.; Sun, Q., Recent advances in breaking scaling relations for effective electrochemical conversion of CO2. Adv. Energy Mater. 2016, 6 (17).

49. Lucci, F. R.; Lawton, T. J.; Pronschinske, A.; Sykes, E. C. H., Atomic Scale Surface Structure of Pt/Cu(111) Surface Alloys. J. Phys. Chem. C 2014, 118 (6), 3015-3022.

50. Lucci, F. R.; Liu, J.; Marcinkowski, M. D.; Yang, M.; Allard, L. F.; Flytzani-Stephanopoulos, M.; Sykes, E. C. H., Selective hydrogenation of 1,3-butadiene on platinum-copper alloys at the single-atom limit. Nat Commun 2015, 6, 8550. 
51. Lucci, F. R.; Marcinkowski, M. D.; Lawton, T. J.; Sykes, E. C. H., H2 Activation and Spillover on Catalytically Relevant Pt-Cu Single Atom Alloys. J. Phys. Chem. C 2015, 119 (43), 24351-24357.

52. Liu, J.; Lucci, F. R.; Yang, M.; Lee, S.; Marcinkowski, M. D.; Therrien, A. J.; Williams, C. T.; Sykes, E. C. H.; Flytzani-Stephanopoulos, M., Tackling CO Poisoning with Single-Atom Alloy Catalysts. J. Am. Chem. Soc. 2016, 138 (20), 6396-6399.

53. Darby, M. T.; Réocreux, R.; Sykes, E. C. H.; Michaelides, A.; Stamatakis, M., Elucidating the Stability and Reactivity of Surface Intermediates on Single-Atom Alloy Catalysts. ACS Catalysis 2018, 8 (6), 5038-5050.

54. Boucher, M. B.; Zugic, B.; Cladaras, G.; Kammert, J.; Marcinkowski, M. D.; Lawton, T. J.; Sykes, E. C. H.; Flytzani-Stephanopoulos, M., Single atom alloy surface analogs in Pd0.18Cu15 nanoparticles for selective hydrogenation reactions. PCCP 2013, 15 (29), 12187-12196.

55. Liu, J.; Shan, J.; Lucci, F. R.; Cao, S.; Sykes, E. C. H.; Flytzani-Stephanopoulos, M., Palladium-gold single atom alloy catalysts for liquid phase selective hydrogenation of 1-hexyne. Catal. Sci. Technol. 2017, 7 (19), 4276-4284.

56. McCue, A. J.; Anderson, J. A., CO induced surface segregation as a means of improving surface composition and enhancing performance of CuPd bimetallic catalysts. J. Catal. 2015, 329, 538-546.

57. McCue, A. J.; Gibson, A.; Anderson, J. A., Palladium assisted copper/alumina catalysts for the selective hydrogenation of propyne, propadiene and propene mixed feeds. Chem. Eng. J. 2016, 285, 384-391.

58. Cao, X. X.; Mirjalili, A.; Wheeler, J.; Xie, W.; Jang, B. W. L., Investigation of the preparation methodologies of $\mathrm{Pd}$-Cu single atom alloy catalysts for selective hydrogenation of acetylene. Front. Chem. Sci. Eng. 2015, 9 (4), 442-449.

59. Cao, X. X.; Mirjalili, A.; Xie, W. T.; Jang, B., Investigation of Pd-Cu single atom alloy catalysts for selective hydrogenation of acetylene in ethylene. Abstr. Pap. Am. Chem. Soc. 2015, 249.

60. Zhang, L.; Wang, A.; Miller, J. T.; Liu, X.; Yang, X.; Wang, W.; Li, L.; Huang, Y.; Mou, C. Y.; Zhang, T., Efficient and Durable Au Alloyed Pd Single-Atom Catalyst for the Ullmann Reaction of Aryl Chlorides in Water. ACS Catalysis 2014, 4 (5), 1546-1553.

61. Pei, G. X.; Liu, X. Y.; Wang, A.; Lee, A. F.; Isaacs, M. A.; Li, L.; Pan, X.; Yang, X.; Wang, X.; Tai, Z.; Wilson, K.; Zhang, T., Ag Alloyed Pd Single-Atom Catalysts for Efficient Selective Hydrogenation of Acetylene to Ethylene in Excess Ethylene. ACS Catalysis 2015, 5 (6), 3717-3725.

62. Pei, G. X.; Liu, X. Y.; Yang, X.; Zhang, L.; Wang, A.; Li, L.; Wang, H.; Wang, X.; Zhang, T., Performance of Cu-Alloyed Pd Single-Atom Catalyst for Semihydrogenation of Acetylene under Simulated Front-End Conditions. ACS Catalysis 2017, 7 (2), 1491-1500.

63. Kruppe, C. M.; Krooswyk, J. D.; Trenary, M., Selective Hydrogenation of Acetylene to Ethylene in the Presence of a Carbonaceous Surface Layer on a Pd/Cu(111) Single-Atom Alloy. ACS Catalysis 2017, 7 (12), 8042-8049.

64. Hasegawa, S.; Takano, S.; Yamazoe, S.; Tsukuda, T., Prominent hydrogenation catalysis of a PVPstabilized Au34 superatom provided by doping a single Rh atom. Chem. Commun. 2018, 54 (46), 59155918.

65. Marcinkowski, M. D.; Darby, M. T.; Liu, J.; Wimble, J. M.; Lucci, F. R.; Lee, S.; Michaelides, A.; Flytzani-Stephanopoulos, M.; Stamatakis, M.; Sykes, E. C. H., Pt/Cu single-atom alloys as coke-resistant catalysts for efficient $\mathrm{C}-\mathrm{H}$ activation. Nat Chem 2018.

66. Bellisario, D. O.; Han, J. W.; Tierney, H. L.; Baber, A. E.; Sholl, D. S.; Sykes, E. C. H., Importance of Kinetics in Surface Alloying: A Comparison of the Diffusion Pathways of Pd and Ag Atoms on $\mathrm{Cu}(111)$. J. Phys. Chem. C 2009, 113 (29), 12863-12869.

67. Tierney, H. L.; Baber, A. E.; Kitchin, J. R.; Sykes, E. C. H., Hydrogen Dissociation and Spillover on Individual Isolated Palladium Atoms. Phys. Rev. Lett. 2009, 103 (24), 246102. 
68. Baber, A. E.; Tierney, H. L.; Lawton, T. J.; Sykes, E. C. H., An Atomic-Scale View of Palladium Alloys and their Ability to Dissociate Molecular Hydrogen. ChemCatChem 2011, 3 (3), 607-614.

69. Kyriakou, G.; Boucher, M. B.; Jewell, A. D.; Lewis, E. A.; Lawton, T. J.; Baber, A. E.; Tierney, H. L.; Flytzani-Stephanopoulos, M.; Sykes, E. C. H., Isolated Metal Atom Geometries as a Strategy for Selective Heterogeneous Hydrogenations. Science 2012, 335 (6073), 1209-1212.

70. Lewis, E. A.; Le, D.; Jewell, A. D.; Murphy, C. J.; Rahman, T. S.; Sykes, E. C. H., Visualization of Compression and Spillover in a Coadsorbed System: Syngas on Cobalt Nanoparticles. ACS Nano 2013, 7 (5), 4384-4392.

71. Marcinkowski, M. D.; Jewell, A. D.; Stamatakis, M.; Boucher, M. B.; Lewis, E. A.; Murphy, C. J.; Kyriakou, G.; Sykes, E. C. H., Controlling a spillover pathway with the molecular cork effect. Nat Mater 2013, $12(6), 523-528$.

72. Kyriakou, G.; Davidson, E. R. M.; Peng, G.; Roling, L. T.; Singh, S.; Boucher, M. B.; Marcinkowski, M. D.; Mavrikakis, M.; Michaelides, A.; Sykes, E. C. H., Significant Quantum Effects in Hydrogen Activation. ACS Nano 2014, 8 (5), 4827-4835.

73. Lucci, F. R.; Darby, M. T.; Mattera, M. F. G.; Ivimey, C. J.; Therrien, A. J.; Michaelides, A.; Stamatakis, M.; Sykes, E. C. H., Controlling Hydrogen Activation, Spillover, and Desorption with Pd-Au Single-Atom Alloys. J. Phys. Chem. Lett. 2016, 7 (3), 480-485.

74. Shan, J.; Lucci, F. R.; Liu, J.; El-Soda, M.; Marcinkowski, M. D.; Allard, L. F.; Sykes, E. C. H.; Flytzani-Stephanopoulos, M., Water co-catalyzed selective dehydrogenation of methanol to formaldehyde and hydrogen. Surf. Sci. 2016, 650, 121-129.

75. Wang, Z.-T.; Darby, M. T.; Therrien, A. J.; El-Soda, M.; Michaelides, A.; Stamatakis, M.; Sykes, E. C. H., Preparation, Structure, and Surface Chemistry of Ni-Au Single Atom Alloys. J.Phys. Chem. C 2016, 120 (25), 13574-13580.

76. Kruppe, C. M.; Krooswyk, J. D.; Trenary, M., Polarization-Dependent Infrared Spectroscopy of Adsorbed Carbon Monoxide To Probe the Surface of a Pd/Cu(111) Single-Atom Alloy. J. Phys. Chem. C 2017, 121 (17), 9361-9369.

77. Marcinkowski, M. D.; Liu, J.; Murphy, C. J.; Liriano, M. L.; Wasio, N. A.; Lucci, F. R.; FlytzaniStephanopoulos, M.; Sykes, E. C. H., Selective Formic Acid Dehydrogenation on Pt-Cu Single-Atom Alloys. ACS Catalysis 2017, 7 (1), 413-420.

78. Miura, H.; Endo, K.; Ogawa, R.; Shishido, T., Supported Palladium-Gold Alloy Catalysts for Efficient and Selective Hydrosilylation under Mild Conditions with Isolated Single Palladium Atoms in Alloy Nanoparticles as the Main Active Site. ACS Catalysis 2017, 7 (3), 1543-1553.

79. Wang, Z.-T.; Hoyt, R. A.; El-Soda, M.; Madix, R. J.; Kaxiras, E.; Sykes, E. C. H., Dry Dehydrogenation of Ethanol on Pt-Cu Single Atom Alloys. Top. Catal. 2017.

80. Kim, J.; Roh, C. W.; Sahoo, S. K.; Yang, S.; Bae, J.; Han, J. W.; Lee, H., Highly Durable Platinum Single-Atom Alloy Catalyst for Electrochemical Reactions. Adv. Energy Mater. 2018, 8 (1).

81. Simonovis, J. P.; Hunt, A.; Palomino, R. M.; Senanayake, S. D.; Waluyo, I., Enhanced Stability of Pt-Cu Single-Atom Alloy Catalysts: In Situ Characterization of the Pt/Cu(111) Surface in an Ambient Pressure of CO. J. Phys. Chem. C 2018, 122 (8), 4488-4495.

82. Yang, C. J.; Miao, Z. L.; Zhang, F.; Li, L.; Liu, Y. T.; Wang, A. Q.; Zhang, T., Hydrogenolysis of methyl glycolate to ethanol over a $\mathrm{Pt}-\mathrm{Cu} / \mathrm{SiO} 2$ single-atom alloy catalyst: a further step from cellulose to ethanol. Green Chem. 2018, 20 (9), 2142-2150.

83. Xie, S.; Tsunoyama, H.; Kurashige, W.; Negishi, Y.; Tsukuda, T., Enhancement in Aerobic Alcohol Oxidation Catalysis of Au25 Clusters by Single Pd Atom Doping. ACS Catalysis 2012, 2 (7), 1519-1523.

84. Yang, K.; Yang, B., Identification of the Active and Selective Sites over a Single Pt Atom-Alloyed Cu Catalyst for the Hydrogenation of 1,3-Butadiene: A Combined DFT and Microkinetic Modeling Study. J. Phys. Chem. C 2018, 122 (20), 10883-10891. 
85. Yang, K.; Yang, B., Surface restructuring of Cu-based single-atom alloy catalysts under reaction conditions: the essential role of adsorbates. PCCP 2017, 19 (27), 18010-18017.

86. Ramos, M.; Martinez, A. E.; Busnengo, H. F., H2 dissociation on individual Pd atoms deposited on $\mathrm{Cu}(111)$. PCCP 2012, 14 (1), 303-310.

87. Fu, Q.; Luo, Y., Active Sites of Pd-Doped Flat and Stepped Cu(111) Surfaces for H2 Dissociation in Heterogeneous Catalytic Hydrogenation. ACS Catalysis 2013, 3 (6), 1245-1252.

88. Fu, Q.; Luo, Y., Catalytic Activity of Single Transition-Metal Atom Doped in Cu(111) Surface for Heterogeneous Hydrogenation. J. Phys. Chem. C 2013, 117 (28), 14618-14624.

89. Aich, P.; Wei, H.; Basan, B.; Kropf, A. J.; Schweitzer, N. M.; Marshall, C. L.; Miller, J. T.; Meyer, R., Single-Atom Alloy Pd-Ag Catalyst for Selective Hydrogenation of Acrolein. J. Phys. Chem. C 2015, 119 (32), 18140-18148.

90. Darby, M. T.; Sykes, E. C. H.; Michaelides, A.; Stamatakis, M., Carbon Monoxide Poisoning Resistance and Structural Stability of Single Atom Alloys. Top. Catal. 2018.

91. Cheng, M.-J.; Clark, E. L.; Pham, H. H.; Bell, A. T.; Head-Gordon, M., Quantum Mechanical Screening of Single-Atom Bimetallic Alloys for the Selective Reduction of CO2 to C1 Hydrocarbons. ACS Catalysis 2016, 6 (11), 7769-7777.

92. Thirumalai, H.; Kitchin, J. R., Investigating the Reactivity of Single Atom Alloys Using Density Functional Theory. Top. Catal. 2018.

93. Christensen, A.; Ruban, A. V.; Stoltze, P.; Jacobsen, K. W.; Skriver, H. L.; Nørskov, J. K.; Besenbacher, F., Phase diagrams for surface alloys. Phys. Rev. B 1997, 56 (10), 5822-5834.

94. Sansa, M.; Dhouib, A.; Guesmi, H., Density functional theory study of CO-induced segregation in gold-based alloys. J. Chem. Phys. 2014, 141 (6), 064709.

95. Oğuz, I.-C.; Mineva, T.; Guesmi, H., The effect of Pd ensemble structure on the $\mathrm{O} 2$ dissociation and CO oxidation mechanisms on Au-Pd(100) surface alloys. J. Chem. Phys. 2018, 148 (2), 024701.

96. Greeley, J.; Nørskov, J. K., A general scheme for the estimation of oxygen binding energies on binary transition metal surface alloys. Surf. Sci. 2005, 592 (1-3), 104-111.

97. Wang, Z.; Hu, P., Formulating the bonding contribution equation in heterogeneous catalysis: a quantitative description between the surface structure and adsorption energy. PCCP 2017, 19 (7), 5063 5069.

98. Wang, Z.; Hu, P., A rational catalyst design of $\mathrm{CO}$ oxidation using the bonding contribution equation. Chem. Commun. 2017, 53 (58), 8106-8109.

* We have made some minor corrections to the data in reference 53 , as some calculations were not fully converged, and we provide the values of all data points of Figure 5 in the supporting information. None of the conclusions of our previous work have changed as a result of these corrections. 


\section{Supporting Information:}

\section{Lonely Atoms with Special Gifts: Breaking Linear Scaling Relationships in Heterogeneous Catalysis with Single-Atom Alloys}

Matthew T. Darby ${ }^{\mathrm{a}}$, Michail Stamatakis ${ }^{\mathrm{a}}$, Angelos Michaelides ${ }^{\mathrm{b}}$ and E. Charles. H. Sykes ${ }^{\mathrm{c}}$

a Department of Chemical Engineering, University College London, 203 Roberts Building, Torrington Place, London, WC1E 7JE, United Kingdom

b Thomas Young Centre, London Centre for Nanotechnology and Department of Physics and Astronomy, University College London, Gower Street, London WC1E 6BT, United Kingdom c Department of Chemistry, Tufts University, 62 Talbot Ave., Medford, Massachusetts 02155, United States. 


\section{Free Energy Driving Force for Spillover in Surfaces with Two Site Types}

We calculate the thermodynamic driving force for spillover of one adsorbate species in a surface with two site types, assuming that lateral interactions are negligible.

\section{Binding to Different Site Types}

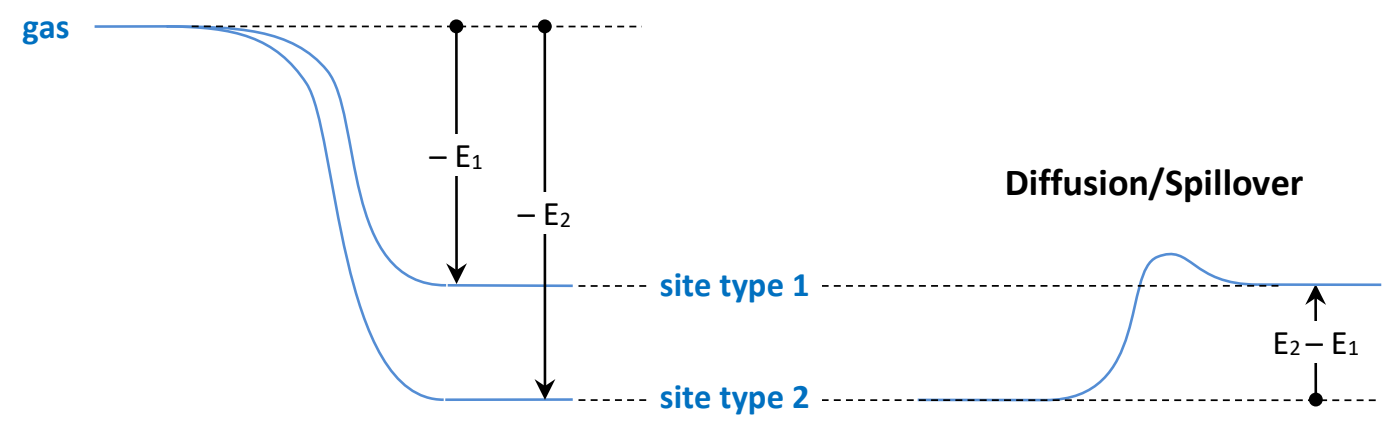

We focus on the equilibrium behavior of this system neglecting the specifics of adsorption/desorption or diffusion processes that lead to equilibration. We will work in the Grand Canonical ensemble, in which the chemical potential of the adsorbate will be denoted by $\mu$. To find the equilibrium coverages, let $m_{1}$ and $m_{2}$ be the numbers of sites of type 1 and 2 , respectively, and let $\varphi=\mathrm{m}_{1} / \mathrm{m}_{2}$. Each site can contain at most one particle, so the occupation number is 0 or 1 . With $E_{1}$ and $E_{2}$ we denote the binding energies on the sites of type 1 and 2, respectively; therefore the adsorption energies are $-E_{1}$ and $-E_{2}$. The energy levels for the population of sites of type 1 range from 0 to $\mathrm{m}_{1}$, and thus the energies are:

$\varepsilon_{\mathrm{i}}=-\mathrm{i} \cdot \mathrm{E}_{1} \quad \mathrm{i}=0,1, \ldots \mathrm{m}_{1}$

The degeneracy of each energy level can be derived by noticing that since the sites are distinguishable, there are $m_{1}$-choose-i ways to create a microstate with energy $\varepsilon_{i}$ :

$\omega_{\mathrm{i}}=\left(\begin{array}{c}\mathrm{m}_{1} \\ \mathrm{i}\end{array}\right)=\frac{\mathrm{m}_{1} !}{\left(\mathrm{m}_{1}-\mathrm{i}\right) ! \cdot \mathrm{i} !} \quad \mathrm{i}=0,1, \ldots \mathrm{m}_{1}$

Thus, the partition function of adsorbed particles on the set of sites of type 1 will be:

$\Xi_{1}=\sum_{i=0}^{m_{1}} \omega_{i} \cdot e^{-\frac{\varepsilon_{i}-\mu \cdot i}{k_{B} \cdot T}}=\sum_{i=0}^{m_{1}}\left(\begin{array}{c}m_{1} \\ i\end{array}\right) \cdot e^{\frac{i \cdot\left(E_{1}+\mu\right)}{k_{B} \cdot T}}=\left(1+e^{\left.\frac{E_{1}+\mu}{k_{B} \cdot T}\right)^{m_{1}}}\right.$ 
where $\mathrm{T}$ is the temperature, $\mathrm{k}_{\mathrm{B}}$ Boltzmann's constant, and the last equality is due to the binomial theorem, which states:

$$
(1+x)^{n}=\sum_{k=0}^{n}\left(\begin{array}{l}
n \\
k
\end{array}\right) \cdot x^{k}
$$

Hence, the average number of particles at equilibrium in site types 1 (denoted as $n_{1}$ ), can be evaluated as the following derivative of the partition function:

$$
\mathrm{n}_{1}=\frac{\partial \ln \left(\Xi_{1}\right)}{\partial\left(-\frac{-E_{1}}{k_{B} \cdot T}\right)}=m_{1} \cdot\left(1+e^{\frac{E_{1}+\mu}{k_{B} \cdot T}}\right)^{-1} \cdot e^{\frac{E_{1}+\mu}{k_{B} \cdot T}}=\frac{m_{1}}{e^{-\frac{E_{1}+\mu}{k_{B} \cdot T}}+1}
$$

This shows that the coverage fraction $\theta_{1}=\mathrm{n}_{1} / \mathrm{m}_{1}$ follows Fermi-Dirac statistics:

$\theta_{1}=\frac{\mathrm{n}_{1}}{\mathrm{~m}_{1}}=\left(\mathrm{e}^{-\frac{\mathrm{E}_{1}+\mu}{\mathrm{k}_{\mathrm{B}} \cdot \mathrm{T}}}+1\right)^{-1}$

Similarly for $\theta_{2}=\mathrm{n}_{2} / \mathrm{m}_{2}$ :

$\theta_{2}=\frac{n_{2}}{m_{2}}=\left(e^{-\frac{E_{2}+\mu}{k_{B} \cdot T}}+1\right)^{-1}$

$\mathrm{n}_{\mathrm{p}}=\mathrm{n}_{1}+\mathrm{n}_{2}$

To refresh our memory on the notation: $E_{1}$ and $E_{2}$ are the binding energies on the two sites types (the more positive the stronger the binding), $\mathrm{T}$ is the temperature, $\mathrm{k}_{\mathrm{B}}$ is Boltzmann's constant, $\mathrm{n}_{\mathrm{p}}$ is the total number of particles and $\mu$ the chemical potential of the two "phases", namely the particles on the sites of type 1 and those on sites of type 2 . One can either treat $n_{p}$ as known if the total coverage is known, or alternatively, $\mu$ can be treated as known (but of course one can specify either $n_{p}$ or $\mu$ ).

The Grand potentials, $\Phi_{\mathrm{G}}$, of the adsorbate on sites of types $\mathrm{j}=1,2$ can be calculated as: 
$\Phi_{G, j}=-k_{B} \cdot T \cdot \ln \left(\Xi_{j}\right)=-k_{B} \cdot T \cdot m_{j} \cdot \ln \left(1+e^{\frac{E_{j}+\mu}{k_{B} \cdot T}}\right) \quad j=1,2$

The Grand potential is therefore proportional to the number of sites (term $\mathrm{m}_{\mathrm{j}}$ ), which creates a thermodynamic driving force for the adsorbate to spillover to the sites with higher multiplicity on the surface.

Some subtle points may need to be clarified with an example: let us assume $\mathrm{m}_{1} \ll \mathrm{m}_{2}$ and $\mathrm{E}_{1}$ $\approx \mathrm{E}_{2}$. Equation (9) essentially says that the domain of sites of type 2 has a much higher "capacity" and therefore it is ready to accept more "stuff", i.e. a higher number of molecules (extensive quantity). However, if someone was to measure the coverage of the adsorbate (intensive quantity) on sites of type 1 and 2, they would find similar values, due to equations (6) and (7) and because we have assumed similar binding energies. Thus, when we say "high propensity for spillover to sites X", this should not be interpreted as a tendency to have higher coverages at sites $\mathrm{X}$. The coverage is a function of binding energy and chemical potential (and of course interaction strengths in more complicated models; this was neglected in this simple analysis).

Another way to view this, is by looking back at the relation of chemical potential with respect to the number of molecules; from equations (6) and (7):

$$
\begin{aligned}
& \mu=-E_{1}+k_{B} \cdot T \cdot \ln \left(\frac{\theta_{1}}{1-\theta_{1}}\right) \\
& \mu=-E_{2}+k_{B} \cdot T \cdot \ln \left(\frac{\theta_{2}}{1-\theta_{2}}\right)
\end{aligned}
$$

The site multiplicity does not appear explicitly in the equations above; however, taking into account that $\mathrm{m}_{1} \ll \mathrm{m}_{2}$ (and $\mathrm{E}_{1} \approx \mathrm{E}_{2}$ ) in our example, it follows that the sites of type 2 will need to "contain" many more adsorbate molecules to achieve equilibrium with the sites of type 1 . 


\section{Dissociating Species}

\begin{tabular}{|c|c|c|c|c|c|c|c|c|c|c|}
\hline \multirow[b]{2}{*}{ Surface } & \multicolumn{2}{|c|}{$\mathrm{H}_{2}$} & \multicolumn{2}{|c|}{$\mathrm{CH}_{4}$} & \multicolumn{2}{|c|}{$\mathrm{NH}_{3}$} & \multicolumn{2}{|c|}{$\mathrm{CH}_{3} \mathrm{OH}$} & \multicolumn{2}{|c|}{$\mathrm{CO}_{2}$} \\
\hline & $\begin{array}{c}E_{a} \\
(e V)\end{array}$ & $\begin{array}{c}\Delta \mathrm{E}_{\mathrm{R \times n}} \\
(\mathrm{eV})\end{array}$ & $\begin{array}{c}E_{a} \\
(e V)\end{array}$ & $\begin{array}{c}\Delta \mathrm{E}_{\mathrm{Rxn}} \\
(\mathrm{eV})\end{array}$ & $\begin{array}{c}E_{a} \\
(e V)\end{array}$ & $\begin{array}{c}\Delta \mathrm{E}_{\mathrm{R} \times \mathrm{n}} \\
(\mathrm{eV})\end{array}$ & $\begin{array}{c}E_{a} \\
(e V)\end{array}$ & $\begin{array}{c}\Delta \mathrm{E}_{\mathrm{Rxn}} \\
(\mathrm{eV})\end{array}$ & $\begin{array}{c}E_{a} \\
(e V)\end{array}$ & $\begin{array}{c}\Delta \mathrm{E}_{\mathrm{R \times n}} \\
(\mathrm{eV})\end{array}$ \\
\hline $\mathrm{Ag}(111)$ & 1.10 & 0.64 & 2.11 & 1.60 & 2.14 & 1.45 & 1.55 & 0.87 & 2.44 & 2.41 \\
\hline $\mathrm{Au}(111)$ & 1.11 & 0.47 & 1.78 & 1.37 & 2.15 & 1.60 & 1.74 & 1.39 & 2.95 & 2.86 \\
\hline $\mathrm{Cu}(111)$ & 0.48 & -0.09 & 1.48 & 0.64 & 1.69 & $0.53^{*}$ & 1.05 & -0.12 & 1.20 & 0.71 \\
\hline $\mathrm{Ni}(111)$ & 0.07 & -0.84 & 0.75 & $-0.10^{*}$ & 1.21 & 0.03 & 0.80 & -0.48 & 0.43 & $-1.09 \dagger$ \\
\hline $\operatorname{Pd}(111)$ & 0.04 & -0.79 & 0.68 & 0.17 & 1.48 & 0.41 & 0.94 & $0.15^{*}$ & 1.26 & $-0.03+$ \\
\hline $\operatorname{Pt}(111)$ & 0.00 & $-1.01^{*}$ & 0.58 & -0.15 & 1.27 & 0.49 & 0.70 & 0.44 & 1.01 & 0.57 \\
\hline $\operatorname{Rh}(111)$ & 0.00 & $-1.10^{*}$ & 0.56 & 0.10 & 1.32 & 0.09 & 0.78 & -0.10 & 0.41 & -0.75 \\
\hline $\mathrm{NiAg}(111)$ & 0.18 & -0.02 & 0.82 & 0.69 & 1.32 & 0.80 & 0.92 & 0.15 & 0.95 & 0.97 \\
\hline $\mathrm{NiAu}(111)$ & 0.36 & 0.16 & 0.94 & $0.87^{*}$ & 1.72 & $1.18^{*}$ & 1.20 & 0.70 & 1.52 & 1.64 \\
\hline $\mathrm{NiCu}(111)$ & 0.13 & -0.47 & 0.82 & $0.35^{*}$ & 1.26 & 0.37 & 0.86 & -0.38 & 0.60 & -0.12 \\
\hline $\mathrm{PdAg}(111)$ & 0.32 & 0.01 & 1.21 & 1.02 & 1.67 & 1.12 & 1.09 & 0.46 & 1.97 & 1.58 \\
\hline $\mathrm{PdAu}(111)$ & 0.42 & 0.10 & 1.18 & 1.02 & 2.00 & 1.46 & 1.57 & 1.22 & 2.34 & 2.14 \\
\hline $\mathrm{PdCu}(111)$ & 0.33 & -0.37 & 1.19 & 0.80 & 1.57 & 0.65 & 0.87 & -0.06 & 1.17 & 0.48 \\
\hline PtAg(111) & 0.00 & -0.25 & 0.94 & 0.59 & 1.54 & 0.92 & 0.80 & 0.37 & 1.73 & 1.26 \\
\hline PtAu(111) & 0.02 & -0.14 & 0.85 & 0.56 & 1.91 & 1.31 & 1.28 & 1.17 & 2.01 & 1.73 \\
\hline $\mathrm{PtCu}(111)$ & 0.01 & -0.40 & $1.01^{*}$ & 0.53 & 1.46 & 0.63 & 0.74 & -0.03 & 0.97 & 0.27 \\
\hline $\mathrm{RhAg}(111)$ & 0.01 & -0.07 & 0.55 & 0.35 & 1.31 & 0.73 & 0.92 & $0.13^{*}$ & 1.10 & 0.90 \\
\hline $\operatorname{RhAu}(111)$ & 0.08 & 0.06 & 0.61 & 0.47 & 1.72 & 1.16 & 1.12 & 0.82 & 1.21 & 0.76 \\
\hline $\mathrm{RhCu}(111)$ & 0.05 & -0.24 & 0.64 & 0.34 & 1.33 & 0.44 & $0.84^{*}$ & $-0.11^{*}$ & 0.63 & -0.29 \\
\hline
\end{tabular}

Table S1: Activation energies $\left(\mathrm{E}_{\mathrm{a}}\right)$ and reaction energies before spillover $\left(\Delta \mathrm{E}_{\mathrm{Rxn}}\right)$ for the bond dissociation reactions of $\mathrm{H}_{2}, \mathrm{CH}_{4}, \mathrm{NH}_{3}, \mathrm{CH}_{3} \mathrm{OH}(\mathrm{O}-\mathrm{H})$ and $\mathrm{CO}$ on pure metal and SAA surfaces. Some minor corrections to the data tables from Ref 53 are denoted by * and we have further optimized two final states to lower lying minima on the potential energy surface which we denote by + . 


\begin{tabular}{|c|c|c|c|c|c|}
\hline \multirow[b]{3}{*}{ Surface } & \multicolumn{5}{|c|}{ Dissociating Species } \\
\hline & $\mathrm{H}_{2}$ & $\mathrm{CH}_{4}$ & $\mathrm{NH}_{3}$ & $\mathrm{CH}_{3} \mathrm{OH}$ & $\mathrm{CO}_{2}$ \\
\hline & $\begin{array}{c}\Delta \mathrm{E}_{\text {Rxn,Spill }} \\
(\mathrm{eV})\end{array}$ & $\begin{array}{c}\Delta \mathrm{E}_{\text {Rxn,Spill }} \\
(\mathrm{eV})\end{array}$ & $\begin{array}{c}\Delta \mathrm{E}_{\text {Rxn,Spill }} \\
(\mathrm{eV})\end{array}$ & $\begin{array}{c}\Delta \mathrm{E}_{\text {Rxn,Spill }} \\
(\mathrm{eV})\end{array}$ & $\begin{array}{c}\Delta \mathrm{E}_{\text {Rxn,Spill }} \\
(\mathrm{eV})\end{array}$ \\
\hline $\operatorname{NiAg}(111)$ & 0.84 & 1.57 & 1.77 & 1.05 & 2.46 \\
\hline $\mathrm{NiAu}(111)$ & 0.77 & 1.28 & 2.13 & 1.72 & 2.80 \\
\hline $\mathrm{NiCu}(111)$ & -0.08 & 0.64 & 0.69 & -0.11 & 0.49 \\
\hline $\operatorname{PdAg}(111)$ & 0.55 & 1.58 & 1.48 & 0.79 & 2.46 \\
\hline $\operatorname{PdAu}(111)$ & 0.56 & 1.28 & 1.85 & 1.50 & 2.79 \\
\hline $\mathrm{PdCu}(111)$ & -0.35 & 0.65 & 0.47 & -0.11 & 0.50 \\
\hline $\operatorname{PtAg}(111)$ & 0.64 & 1.57 & 1.48 & 0.82 & 2.47 \\
\hline PtAu(111) & 0.65 & 1.28 & 1.95 & 1.47 & 2.77 \\
\hline $\mathrm{PtCu}(111)$ & -0.34 & 0.64 & 0.44 & -0.08 & 0.50 \\
\hline $\operatorname{RhAg}(111)$ & 1.13 & 1.64 & 1.82 & 1.03 & 2.66 \\
\hline $\operatorname{RhAu}(111)$ & 1.06 & 1.36 & 2.24 & 1.73 & 2.63 \\
\hline $\mathrm{RhCu}(111)$ & 0.15 & 0.70 & 0.77 & 0.02 & 0.45 \\
\hline
\end{tabular}

Table S2: Reaction energies after spillover with respect to the initial state $\left(\triangle \mathrm{E}_{\text {Rxn,Spill }}\right)$ for the bond dissociation reactions of $\mathrm{H}_{2}, \mathrm{CH}_{4}, \mathrm{NH}_{3}, \mathrm{CH}_{3} \mathrm{OH}(\mathrm{O}-\mathrm{H})$ and $\mathrm{CO}_{2}$ on SAA surfaces. 